\title{
Isolation and molecular characterization of methicillin- resistant coagulase-negative staphylococci from nasal flora of healthy humans at three community institutions in Rio de Janeiro City
}

\author{
F. R. Silva, E. M. MATTOS, M. V. S. COIMBRA, B. T. FERREIRA-CARVALHO \\ AND A. M.S. FIGUEIREDO* \\ Universidade Federal do Rio de Janeiro, Laboratório de Biologia Molecular de Bactérias, Departamento de \\ Microbiologia Médica, Instituto de Microbiologia Prof. Paulo de Góes, Centro de Ciências da Saúde, \\ Bloco I, Cidade Universitária, Rio de Janeiro, RJ, Brazil
}

(Accepted 28 March 2001)

\section{SUMMARY}

We describe the isolation and molecular characterization of methicillin-resistant coagulasenegative staphylococci (MRCNS) from the nasal flora of healthy humans from three institutions located in Rio de Janeiro City. Swabs were obtained from the nares of students attending a non-residential public school and adults from two military quarters. Isolates of staphylococci were tested for the presence of the mecA gene by hybridization with a specific probe. S. epidermidis was the most frequent MRCNS (38 of the total 45 CNS isolated). Twenty-five percent of nasal staphylococcal carriers studied were colonized with MRCNS. Pulsed-field gel electrophoresis (PFGE) of SmaI-digested genomic DNA was carried out to study the clonality of the methicillin-resistant S. epidermidis (MRSE) isolates. In addition to cross-colonization among individuals belonging to the same institution, familial crosscolonization appeared to contribute to the spread of the methicillin-resistant isolates among two inter-communicable institutions. Indeed, the wide genomic diversity among the MRSE flora suggests that the spread of the mec $A$ gene among these isolates might also have occurred via horizontal transmission. Despite the limited number of institutions analysed, it is reasonable to conclude that our data do not represent a situation unique to the three organizations but may reflect other communities in Rio with respect to transmission of MRCNS.

\section{INTRODUCTION}

Coagulase-negative staphylococci (CNS) are natural inhabitants of human skin but are also among the most frequently isolated bacteria in clinical specimens [1]. Recently, CNS have emerged as a significant cause of hospital-acquired infections [1,2]. The increased use of medical devices, such as intravascular catheters and other medical prostheses in seriously ill and immunocompromised patients, is an important contributing factor for the increased isolation of these bacteria in opportunist infections [3]. CNS have been

* Author for correspondence. reported to account for $25 \%$ of all nosocomial bacteraemia cases and for about $45 \%$ of these infections in intensive care units (ICU) in Europe [4]. Staphylococcus epidermidis is the dominant species but $S$. haemolyticus is also of importance [1].

Infections caused by methicillin-resistant coagulasenegative staphylococci (MRCNS) represent a therapeutic challenge and these strains may account for $60-90 \%$ of all CNS isolated in hospitals [4-6]. The $m e c A$ gene determining methicillin resistance is widely disseminated among CNS species including S. epidermidis, S. haemolyticus, S. hominis, S. simulans, $S$. saprophyticus, S. sciuri, S. capitis, S. warneri and $S$. 
caprae [7-13]. This widespread distribution of mecA might be due to horizontal transmission among CNS and $S$. aureus isolates [8, 14]. Frequently, CNS are multiresistant to antimicrobial agents but susceptible to vancomycin although isolates with decreased susceptibility to vancomycin and teicoplanin have been described [15-17].

Antimicrobial resistance is recognized as a substantial problem for a number of community-acquired infectious diseases. However, few studies have attempted to assess the extent of colonization by resistant bacteria of healthy individuals in the community $[18,19]$. The normal non-pathogenic flora of ambulatory and hospitalized individuals may represent a large and constant reservoir of resistance genes which are potentially transferable to virulent bacteria [1, 14]. Thus, tracing the dissemination of resistant bacterial populations and their genomic diversity may inform the epidemiological and evolutionary overview of their antimicrobial resistance and provide new insights into means of control. There are no recent data in the literature on the frequency of methicillin resistance among the CNS nasal flora of healthy individuals. We therefore investigated the dissemination of the mecA gene among CNS nasal isolates from healthy individuals in three institutions, located in Rio de Janeiro City, and studied their genomic diversity using pulsed-field gel electrophoresis (PFGE) of chromosomal DNA digests.

\section{METHODS}

\section{Nasal sampling}

We analysed 316 paired nasal swabs randomly obtained from 57 healthy children (6-13 years old) in four classes from a non-residential public school located in Rio de Janeiro City and from 101 adults (18-49 years old) from two military barracks. Barrack 1 (50 adults) and barrack 2 (51 adults) are both located in Rio and the latter is situated about $50 \mathrm{~m}$ from the public school. Approximately one-third of the military personnel at barrack 2 sent their children to the public school. Barrack 1 is totally independent from barrack 2 and from the public school, and is about $6 \mathrm{~km}$ from barrack 2. The population studied represented $10 \%$ of the total individuals of these three communities. Nasal swabs were transported to the laboratory and processed immediately. One of each pair of swabs from each individual was put into $2 \mathrm{ml}$ of trypticase soy broth (TSB) containing $7 \cdot 5 \% \mathrm{NaCl}$ $(\mathrm{w} / \mathrm{v})$ and $10 \mathrm{mg} / \mathrm{l}$ of methicillin. The broth was incubated at $35^{\circ} \mathrm{C}$ for $24-48 \mathrm{~h}$ and subcultured on trypticase soy agar (TSA) which was incubated at $35^{\circ} \mathrm{C}$ for $18 \mathrm{~h}$. The second swab was streaked directly on TSA and incubated at $35^{\circ} \mathrm{C}$ for $18 \mathrm{~h}$. Staphylococci were presumptively identified by Gram-stain and by catalase and coagulase tests. Identification of methicillin-resistant strains was confirmed in the Autoscan, Microscan System (Dade Behringer, Sacramento, USA).

\section{Methicillin resistance}

Methicillin-resistant isolates were identified by subculturing $100 \mu \mathrm{l}$ of a turbid broth culture on TSA containing $25 \mathrm{mg} / 1$ of methicillin, incubated at $35^{\circ} \mathrm{C}$ for $24-48 \mathrm{~h}$ [20-22]. Isolates were stored in $12 \%$ glycerol broth at $-70{ }^{\circ} \mathrm{C}$. Chromosomal DNA from each isolate was prepared as described previously [23], with a lysis mixture containing mutanolysin $(65 \mathrm{U} / \mathrm{ml})$, lysozyme $\left(7 \times 10^{4} \mathrm{U} / \mathrm{ml}\right)$ and BRIJ 35 $(0.05 \% ; \mathrm{v} / \mathrm{v})$.

E. coli plasmid (pMF13) [24] was purified using a Flex-Prep kit (Amersham-Pharmacia Biotechnology, Piscataway, USA). The $X b a \mathrm{I}-P_{s t \mathrm{I}} \mathrm{DNA}$ fragment of $1196 \mathrm{bp}$ of pMF13 was excised from $0 \cdot 8 \%$ agarose gel using the Sephaglas Band Prep kit (AmershamPharmacia) and fluorescein-labelled probe by the enhanced chemiluminescence (ECL) gene labelling system (Amersham-Pharmacia). Chromosomal DNA was assayed for the mecA gene by dot-blot hybridization procedures using the ECL detection system.

\section{PFGE}

Chromosomal DNA digested with the restriction endonuclease $S m a \mathrm{I}$ was separated by PFGE as described previously [25]. DNA banding patterns were analysed as follows. Isolates with identical DNA patterns were assigned the same capital letter; isolates varying by 1-6 bands from this were considered variants of a unique pattern and were differentiated by

a number. Strains differing by more than six bands were assigned different capital letters and considered unrelated.

\section{Susceptibility tests}

Disk diffusion tests were carried out as recommended by the National Committee for Clinical Laboratory 
Standards (NCCLS) [26]. The following antimicrobial agents (Cecon, São Paulo, Brazil) were tested: oxacillin $1 \mu \mathrm{g}$, penicillin $10 \mathrm{U}$, clindamycin $2 \mu \mathrm{g}$, chloramphenicol $30 \mu \mathrm{g}$, ofloxacin $5 \mu \mathrm{g}$, erythromycin $15 \mu \mathrm{g}$, tetracycline $30 \mu \mathrm{g}$, gentamicin $10 \mu \mathrm{g}$, trimethoprim-sulfamethoxazole $1.25-23.75 \mu \mathrm{g}$, vancomycin $30 \mu \mathrm{g}$ and rifampin $5 \mu \mathrm{g}$. Mupirocin $(5 \mu \mathrm{g})$ disks were purchased from Oxoid, Brasil Ltda., São Paulo, Brazil.

\section{RESULTS}

Carriers

Enrichment of nasal swabs in methicillin broth allowed the recovery of 38 MRCNS isolates (24\%) from the 158 volunteers. However, direct plating of swabs on antibiotic free medium yielded only $4.4 \%$ of MRCNS from the sample population. Only 7 of 158 $(4 \%)$ individuals had been hospitalized in the 6month period prior to the study. Eight $(5 \%)$ had received antibiotics within that period and $31(20 \%)$ had had familial contact with hospitalized persons or health care personnel. Although none of the individuals colonized with MRCNS had been in hospitals or had contact with patients, 4 of the 8 that had previous antimicrobial therapy were colonized with methicillin-resistant isolates.

\section{Methicillin-resistance}

All but 7 of 45 isolates that hybridized with the mec $A$ probe were identified as $S$. epidermidis. Four were $S$. haemolyticus and the remainder were $S$. hominis, $S$. warneri and S. equorum. There was therefore an exact correlation between growth on the screening agar containing $25 \mathrm{mg} / 1$ methicillin and detection of mecA gene by hybridization with the specific probe. With rare exceptions, MRCNS isolates were susceptible to the majority of non $\beta$-lactam antimicrobials tested. However, resistance was observed to tetracycline $(62 \%)$, erythromycin $(42 \%)$ and trimethoprimsulfamethoxazole $(27 \%)$. Multiresistance to 5 groups of drugs was exhibited by 12 isolates.

\section{Genomic diversity}

A total of 17 unique DNA patterns (A-Q) was discerned among the 29 MRSE isolates studied. (Table
Table 1. Genomic diversity of 28 methicillin-resistant $\mathrm{S}$. epidermidis isolates obtained from the nasal flora of healthy humans from three institutions in Rio de Janeiro, Brazil

\begin{tabular}{|c|c|c|}
\hline Strain & Institution & $\begin{array}{l}\text { PFGE } \\
\text { pattern* }\end{array}$ \\
\hline MR01 & \multirow[t]{9}{*}{ Public school } & A \\
\hline MR03 & & $\mathrm{B}_{1}$ \\
\hline MR04 & & $\mathrm{B}_{2}$ \\
\hline MR05 & & $\mathrm{C}$ \\
\hline MR06 & & $\mathrm{D}$ \\
\hline MR07 & & $\mathrm{E}_{1}$ \\
\hline MR08 & & $\mathrm{D}$ \\
\hline MR10 & & $\mathrm{E}_{2}$ \\
\hline MR11 & & $\mathrm{E}_{3}$ \\
\hline MR15 & \multirow[t]{10}{*}{ Barrack 1} & $\mathrm{~F}$ \\
\hline MR16 & & G \\
\hline MR17 & & $\mathrm{H}$ \\
\hline MR18 & & $\mathrm{F}$ \\
\hline MR19 & & I \\
\hline MR20 & & $\mathrm{J}_{1}$ \\
\hline MR21 & & $\mathrm{J}_{2}$ \\
\hline MR22 & & $\mathrm{K}$ \\
\hline MR23 & & $\mathrm{L}$ \\
\hline MR24 & & $\mathrm{J}_{3}$ \\
\hline MR29 & \multirow[t]{9}{*}{ Barrack 2} & $\mathrm{~B}_{3}$ \\
\hline MR30 & & M \\
\hline MR31 & & $\mathrm{B}_{4}$ \\
\hline MR32 & & $\mathrm{N}_{1}$ \\
\hline MR33 & & $\mathrm{O}$ \\
\hline MR37 & & $\mathrm{N}_{2}$ \\
\hline MR39 & & $\mathrm{P}$ \\
\hline MR40 & & Q \\
\hline MR41 & & $\mathrm{D}$ \\
\hline
\end{tabular}

* PFGE pattern; pulsed-field gel electrophoresis patterns of the genomic DNA digested with the SmaI restriction enzyme.

1, Fig. 1). Evidence for cross-colonization among individuals at the same institution was found since isolates with the same or closely related DNA profiles (differing by 1-3 DNA bands) were recovered from the same institution. Cross colonization was verified for patterns $\mathrm{B}$ and $\mathrm{N}$ (isolated from 4 persons at barrack 2), $\mathbf{F}$ and $\mathbf{J}$ (5 individuals from barrack 1 ) and $\mathrm{B}$ and $\mathrm{E}$ (5 persons from the public school). Variants of the patterns $\mathrm{B}$ and $\mathrm{D}$ were also identified among isolates from individuals at barrack 2 and the public school. Sharing of isolates with specific DNA patterns was not observed between individuals from barrack 1 and the school or from barrack 1 and barrack 2 . 
(a)

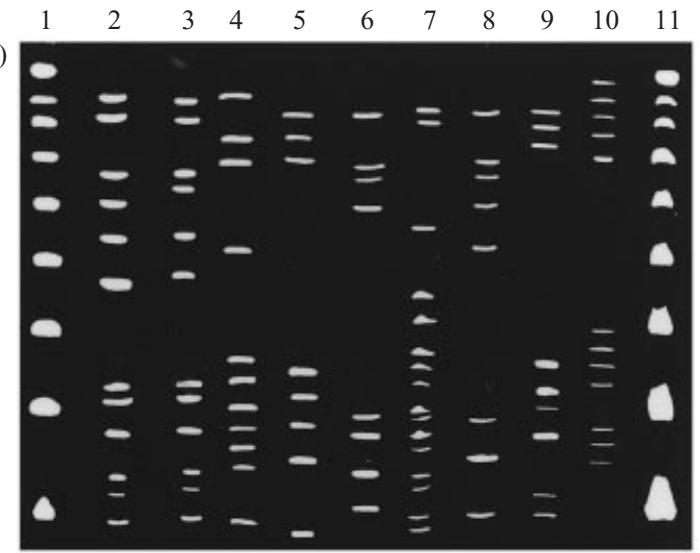

(b)
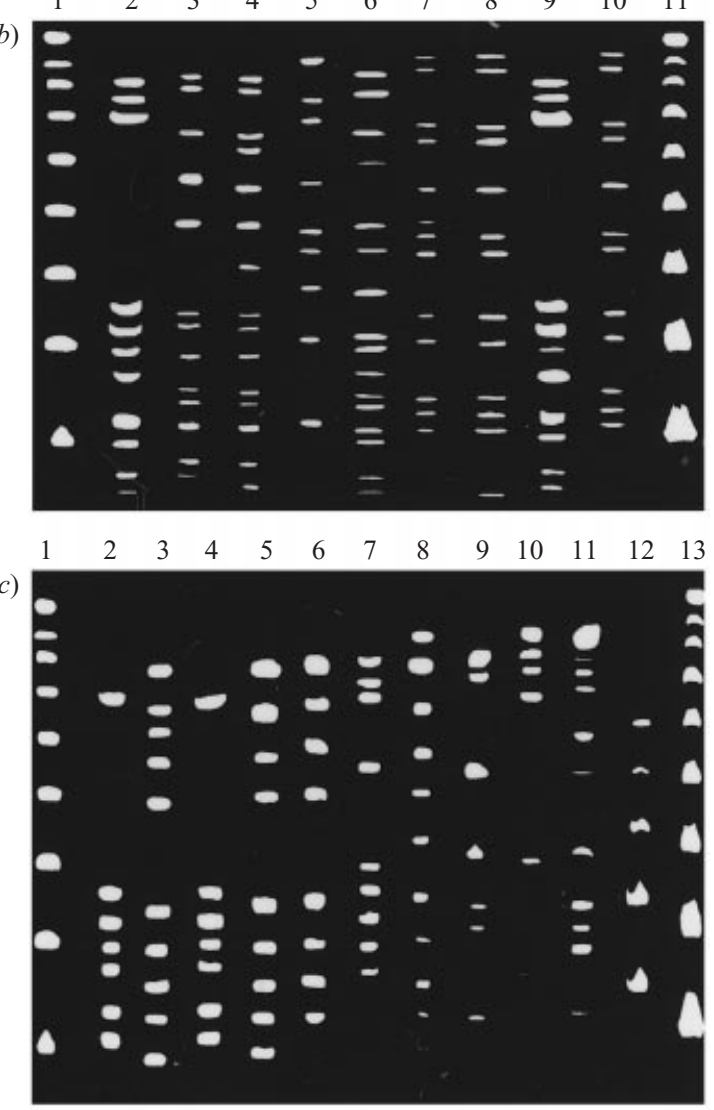

Fig. 1. PFGE patterns of methicillin-resistant Staphylococcus epidermidis (MRSE) isolates from healthy carriers. (a) MRSE isolates from barrack 2. Lanes 1 and $11, \lambda$ ladder (smallest fragment $=100 \mathrm{bp}$ ); Lane 2, strain MR29, PFGE pattern $\mathrm{B}_{3}$; Lane 3, strain MR31, pattern $\mathrm{B}_{4}$; lane 4, MR30, pattern M; lane 5, MR40, pattern Q; lane 6, MR32, pattern $\mathrm{N}_{1}$; lane 7, MR39, pattern P; lane 8, MR37, pattern $\mathrm{N}_{2}$; lane 9, MR41, pattern D; lane 10, MR33, pattern O. (b) MRSE isolates from school pupils. Lane 1 and $11, \lambda$ ladder; lane 2, strain MR6, PFGE pattern D; lane 3, strain MR4, pattern $\mathrm{B}_{2}$; lane 4, MR3, pattern $\mathrm{B}_{1}$; lane 5, MR1, pattern A; lane 6, MR5, pattern $\mathrm{C}$; lane 7, MR7, pattern $\mathrm{E}_{1}$; lane 8, MR11, pattern $\mathrm{E}_{3}$; lane 9, MR8, pattern $\mathrm{D}$; lane 10, MR10, pattern $E_{2}$. (c) MRSE isolates from barrack 1. Lane 1 and 13, $\lambda$ ladder; lane 2, strain MR18, PFGE pattern F;

\section{DISCUSSION}

The emergence of multiresistant bacteria has increased alarmingly in the last three decades and recently, bacteria resistant to all available antimicrobial agents have been reported [6]. This has paralleled the increase of patient populations at high risk of infection due to the frequency and extent of invasive medical interventions and the prolonged survival of many patients with chronic debilitating diseases [6]. In this study we have shown that $24 \%$ of 158 healthy adults and children were colonized with MRCNS in the nose and methicillin resistant $S$. epidermidis (MRSE) accounted for about $84 \%$ of the total MRCNS isolates recovered. The methicillin screening agar has previously been shown to be very sensitive for the detection of methicillin resistance among staphylococci [22]. Heterogeneous resistant isolates (belonging to classes I and II [22]) that have a low frequency of subpopulations expressing methicillin resistance (about $10^{-5}-10^{-8}$ ) were detected by this test, although these isolates may fail to be detected by some NCCLS recommended tests $[20,22]$. The combination of a high inoculum (that allows the detection of small resistant subpopulations) and $25 \mathrm{mg} / 1$ of methicillin (a concentration that impairs the growth of borderline resistant strains but allows the growth of frankly resistant isolates) are the factors responsible for the reliability of this test [22]. Our finding of an absolute correlation between growth on the agar medium and the presence of the mec $A$ gene underlines the value of this test for the screening of isolates.

Considerable genomic diversity was evident among the MRSE isolates and some cross-colonization between individuals within a community was indicated. In addition, there was a suggestion of familial cross-transmission as strains of the same DNA pattern type were recovered from school children and soldiers from a barrack nearby. This is explained by the fact that about one-third of the students attending the school were the children of personnel from the barrack 2 .

In a survey carried out in two hospitals in Rio de Janeiro, (Coimbra MVS, Rocha FS, Figueiredo AMS, unpublished), it was found that MRCNS accounted

lane 3, strain MR24, pattern $\mathrm{J}_{2}$; lane 4, MR15, pattern $\mathrm{F}$; lane 5, MR20, pattern $\mathrm{J}_{1}$; lane 6, MR21, pattern $\mathrm{J}_{2}$; lane 7 , MR19, pattern I; lane 8, MR23, pattern L; lane 9, MR16, pattern $\mathrm{G}$; lane 10, MR22, pattern $\mathrm{K}$; lane 11, MR17, pattern $\mathrm{H}$; lane $12, \lambda$ low range. 
for about $25 \%$ and $33 \%$ of urinary tract infections caused by CNS in hospital outpatients. These results are in accordance with the $24 \%$ MRCNS carriage rate identified in the present study. Furthermore a recent study from the USA [27], carried out with patients from skilled nursing facilities (SNF), reported an overall prevalence of $40 \%$ MRCNS colonization. However, $49 \%$ of newly admitted patients and $60 \%$ of SNF nursing personnel were also colonized with MRCNS. Thus, it is reasonable to speculate that at least a proportion of the individuals sampled here might have been colonized previously in a hospital facility or through cross-colonization by contact with nursing personnel. S. epidermidis was the most frequent staphylococcal species isolated $(84 \% ; 38 / 45)$ and apart from methicillin resistance, isolates from healthy carriers also exhibited varying degrees of resistance to tetracycline, erythromycin and trimethoprim-sulfamethoxazole. To our knowledge there has been no published survey of the pattern of antibacterial drug usage in Rio de Janeiro. The absence of rigid controls of antibiotic usage in the city is likely to be an important selective pressure for the high level of methicillin resistance observed. An association between the use of cloxacillin and cephalosporins and emergence of methicillin resistance in staphylococci has previously been reported [10].

It is important to note that most of the MRCNS carriers had low levels of colonization. Only $4.4 \%$ of the carriers were detected without broth enrichment of swabs followed by culture on methicillin-containing agar, which is consistent with low bacterial numbers. Assuming a population of $10^{2}-10^{3}$ c.f.u. $/ \mathrm{ml}$ of MRCNS in a culture of $10^{7}-10^{8}$ c.f.u. $/ \mathrm{ml}$ of susceptible bacteria, this would explain the increase of the isolation rate to $24 \%$ following enrichment in methicillin broth. Previously, Kernodle et al. [28], using a $6 \mu \mathrm{g}$ nafcillin-containing medium to detect small numbers of methicillin-resistant staphylococci, suggested that the high percentage of MRCNS strains detected on the skin or in the nares of patients after cardiac surgery was derived from methicillin-resistant organisms present in a site preoperatively in much smaller numbers. These organisms emerged in high numbers as a result of surgical antimicrobial prophylaxis.

In summary, we have shown that a quarter of healthy individuals in three separate institutions harboured MRCNS in the nose. Cross-colonization among members of a community and also familial cross-contamination may have played a role in the spread of resistant clones. Due to the wide diversity of DNA profiles among the predominant MRSE isolates it is probable that the spread of the mec locus among these strains might also have occurred via horizontal transmission.

\section{ACKNOWLEDGEMENTS}

This work was supported in part by a grant from Conselho Nacional de Desenvolvimento Científico e Tecnológico (CNPq; Emergent Diseases Programme), Fundação Coordenação de Aperfeiçoamento de Pessoal de Nível Superior (Capes, Proim), Financiadora de Estudos e Projetos (FINEP/ PRONEX) e Fundação de Amparo à Pesquisa do Estado do Rio de Janeiro (FAPERJ).

\section{REFERENCES}

1. Kloos WE, Bannerman TL. Update on clinical significance of coagulase negative staphylococci. Clin Microb Rev 1994; 7: 117-40.

2. Kloos WE, Bannerman TL. Staphylococcus and Micrococcus. In: Murray PR, Baron EJ, Pfaller MA, Tenover FC, Yolken RH, eds. Manual of clinical microbiology. Washington, DC; American Society for Microbiology, 1995; 282-99.

3. Rupp ME, Archer G. Coagulase-negative staphylococci: pathogens associated with medical progress. Clin Infect Dis 1994; 19: 231-45.

4. Spencer RC. Predominant pathogens found in the European prevalence of infections in intensive care study. Eur J Clin Microbiol Infect Dis 1996; 15: 281-5.

5. CDC NNIS System. National Nosocomial Infection Surveillance (NNIS) Semiannual Report. Am J Infect Contr 1995; 23 : 377-85.

6. Tomasz A. Multiple-antibiotic-resistant pathogenic bacteria. N Engl J Med 1994; 330: 1247-51.

7. Archer GL, Penell E. Detection of methicillin resistance in staphylococci using a DNA probe. Antimicrob Agents Chemother 1990; 34: 1720-4.

8. Archer GL, Niemeyer DM. Origin and evolution of DNA associated with resistance to methicillin in staphylococci. Trends Microbiol 1994; 2: 343-7.

9. Couto I, De Lencastre H, Severina E, et al. Ubiquitous presence of a mecA homologue in natural isolates of Staphylococcus sciuri. Microb Drug Resist 1996; 2: 377-91.

10. Mouton RP, Hermans J, Simoons-Smit AM, Hoogkamp-Korstanje JA, Degener JE, van Klingeren B. Correlations between consumption of antibiotics and methicillin resistance in coagulase negative staphylococci. J Antimicrob Chemother 1990; 26: 573-83.

11. Muramaki K, Minamide W, Wada K, Nakamura E, Teraoka H, Watanabe S. Identification of methicillinresistant strains of staphylococci by polymerase chain reaction. J Clin Microbiol 1991; 29: 2240-4. 
12. Pierre J, Williamson R, Bonet M, Gutmann L. Presence of an additional penicillin-binding protein in methicillin-resistant Staphylococcus epidermidis, Staphylococcus haemolyticus, Staphylococcus hominis and Staphylococcus simulans with a low affinity for methicillin, cephalothin and cefamandole. Antimicrob Agents Chemother 1990; 34: 1691-4.

13. Stratten CW, Gelfand MS, Geberding JL, Chambers HF. Characterization of mechanisms of resistance to $\beta$-lactam antibiotics in methicillin-resistant strains of Staphylococcus saprophyticus. Antimicrob Agents Chemother 1990; 34: 1780-2.

14. Archer GL, Scott J. Conjugative transfer genes in staphylococcal isolates from the United States. Antimicrob Agents Chemother 1991; 35: 2500-4.

15. Schwalbe RS, Stapleton JT, Gilligan PH. Emergence of vancomycin resistance in coagulase-negative staphylococci. N Engl J Med 1986; 316: 927-31.

16. Veach LA, Pfaller MA, Barrett M, Koontz FP, Wenzel RW. Vancomycin resistance in Staphylococcus haemolyticus causing colonization and bloodstream infection. J Clin Microbiol 1990; 28: 2064-8.

17. Santos Soares MJ, Silva-Carvalho MC, FerreiraCarvalho BT, Figueiredo AM. Spread of methicillinresistant Staphylococcus aureus belonging to the Brazilian epidemic clone in a general hospital and emergence of heterogeneous resistance to glycopeptide antibiotics among these isolates. J Hosp Infect 2000; 44: 301-8.

18. Calva JJ, Sifuentes Osornio J, Cerón C. Antimicrobial resistance in fecal flora: longitudinal community-based surveillance of children from urban Mexico. Antimicrob Agents Chemother 1996; 40: 1699-702.

19. Nathoo KJ, Chigonde S, Nhembe M, Ali MH, Mason PR. Community-acquired bacteremia in human immunodeficiency virus-infected children in Harare, Zimbabwe. Pediatr Infect Dis J 1996; 12: 1092-7.

20. Resende CA, Figueiredo AMS. Discrimination of methicillin-resistant Staphylococcus aureus from borderline-resistant and susceptible isolates by different methods. J Med Microbiol 1999; 46: 145-9.

21. Falcão MH, Teixeira LA, Ferreira-Carvalho BT, Borges-Neto AA, Figueiredo AMS. Emergence of mupirocin resistance in multiresistant Staphylococcus aureus clinical isolates belonging to Brazilian epidemic clone III:B:A. J Med Microbiol 1999; 48: 515-21.

22. De Lencastre H, Figueiredo AMS, Urban K, Rahal J, Tomasz A. Multiple mechanisms of methicillin resistance and improved methods for detection in clinical isolates of Staphylococcus aureus. Antimicrobial Agents Chemother 1991; 35: 632-9.

23. Sambrook J, Fritsch EF, Maniatis T. In: Molecular cloning, a laboratory manual, 2nd edn. New York: Cold Spring Harbor Laboratory Press, 1989.

24. Matthews PR, Reed CK, Stewart PR. The cloning of chromosomal DNA associated with methicillin and other resistances in Staphylococcus aureus. J Gen Microbiol 1987; 133: 1919-29.

25. Teixeira LA, Resende CA, Ormonde LR, et al. Geographic spread of epidemic multiresistant Staphylococcus aureus clone in Brazil. J Clin Microbiol 1995; 33: $2400-4$.

26. National Committee for Clinical Laboratory Standards. Performance standards for antimicrobial disk susceptibility tests. Approved standard. M2-A4. 4th edn, Villanova, PA, 1990.

27. Lee VL, Cesario T, Tran C, Stone G, Thrupp L. Nasal colonization by methicillin-resistant coagulase-negative Staphylococcus in community skilled nursing facility patients. Am J Infect Contr 2000; 28: 269-72.

28. Kernodle DS, Barg NL, Kaiser AB. Low level colonization of hospitalized patients with methicillinresistant coagulase-negative staphylococci and emergence of the organisms during surgical antimicrobial prophylaxis. Antimicrob Agents Chemother 1988; 32: 202-8. 